\title{
Statins for Primary Prevention of Cardiovascular and Cerebrovascular Events in Diabetic Patients without Established Cardiovascular Diseases: A Meta-Analysis
}

\author{
Authors \\ Y.-H. Chen ${ }^{1}$, B. Feng ${ }^{1}$, Z.-W. Chen ${ }^{2}$ \\ Affiliations \\ 1 Department of Endocrinology, East Hospital, Tongji University, Shanghai, PR China \\ 2 Department of Cardiology, Shanghai Institute of Cardiovascular Diseases, Zhongshan Hospital, Fudan University, \\ Shanghai, PR China
}

Key words
statin
primary prevention
diabetes
coronary heart disease

received $\quad 03.06 .2011$

first decision 22.11.2011

accepted 24.11.2011

Bibliography

DOI http://dx.doi.org/

10.1055/s-0031-1297968

Published online:

December 20, 2011

Exp Clin Endocrinol Diabetes

2012; 120: 116-120

(C) J. A. Barth Verlag in

Georg Thieme Verlag KG

Stuttgart · New York

ISSN 0947-7349

Correspondence

B. Feng, MD Professor of Medicine/Endocrinology

Department of Endocrinology

East Hospital

Tongii University

150 Jimo Road

Shanghai 200120

China

Tel.: + 86/21/3880 4518

Ext.: 3094

Fax: $+86 / 21 / 58793427$

fengbo2010@sohu.com

\section{Abstract}

$\nabla$

Aims: Lipid-lowering medications could lead to a significant reduction in major cardiovascular events in patients with diabetes. However, there was still controversy regarding the use of statins in patients with diabetes for primary prevention. The meta-analysis was performed to evaluate the outcomes of statin-therapy in diabetic patients without established cardiovascular diseases.

Methods: 7 randomized controlled trials of statin- vs. control-therapy in patients with diabetes were included. A total number of 12711 patients were involved. The outcomes of interest were major adverse cardiovascular and cerebrovascular events (MACCE), including myocardial infarction, stroke, all-cause mortality and coronary revascularization.

\section{Introduction}

$\nabla$

Diabetes is one of the major health problems worldwide. According to the results of China National Diabetes and Metabolic Disorders Study, the prevalence of total diabetes in China were 9.7\% [1]. In patients with diabetes, cardiovascular and cerebrovascular disease is the major cause of morbidity and mortality. Current medical evidence suggested that lipid-lowering medications could lead to a significant reduction in major cardiovascular events in patients with diabetes. As one of lipid-lowering medications, statin has been considered to play a very important role in reducing the mortality of coronary artery disease [2-5].

However, with regard to the primary prevention, conflicting evidence has resulted in controversy regarding the use of statins in patients with diabetes without established cardiovascular disease $[6,7]$. Therefore, the present meta-analysis was designed to clarify the efficacy of statin on primary prevention of cardiovascular and cerebro-
Results: A total of 1376 MACCE occurred during follow-up, with $9.54 \%$ (605 patients) in the statin therapy group and $12.10 \%$ (771 patients) in control group. Statin therapy was associated with a significant reduction in the incidence of MACCE $(0.79,95 \%$ CI 0.66-0.95; $P=0.01)$. Meanwhile, the risk of stroke and coronary revascularization were reduced 29 and 26\% in statin therapy group. However, there was no statistical difference of all-cause mortality between statinand control-therapy group (3.73 vs. $4.65 \%$, $P=0.13$ )

Conclusions: For primary prevention in patients with diabetes without established cardiovascular disease, statin therapy could reduce the cardiovascular and cerebrovascular events, but not all-cause mortality.

vascular events in patients with diabetes without established cardiovascular diseases.

\section{Patients and Methods \\ $\nabla$}

Study objective and search strategy

The primary aim of the present meta-analysis was to evaluate the efficacy of statins in the prevention of cardiovascular and cerebrovascular end points in diabetic patients without established cardiovascular diseases.

Using the following key words: "statin" or "HMG-CoA reductase inhibitor" or "atorvastatin" or "simvastatin" or "pravastatin" or "fluvastatin" or "lovastatin" or "rosuvastatin" and "diabetes" or "diabetes mellitus", we searched PUBMED, MEDLINE, EMBASE, and the Cochrane Central Register of Controlled Trials from 1990 to 2011 for all randomized controlled trials and registries reporting outcomes. The search was supplemented by reviews of reference lists for all relevant studies. All relevant reports identified were included without language restriction. 


\section{Study identification and extraction}

Trials that met the following criteria were included: (1) Randomized controlled trials; (2) patients with diabetes without established cardiovascular disease; (3) there was a direct comparison between statins group and control group for primary prevention of vascular events; (4) outcomes including any of major cardiovascular and cerebrovascular events, such as fatal or non-fatal myocardial infarction, cardiac sudden death, coronary revascularization (percutaneous coronary intervention or coronary artery bypass grafting), angina, all-cause mortality and fatal or non-fatal stroke; (5) follow-up duration at least 12 months.

The following information was collected: (1) first author's names; (2) trial names; (3) the year of publication or presentation; (4) target population of trials (5) total sample size and subgroup sample size; (5) history of hypertension, smoking, body mass index and basic HbA1c (6) baseline cholesterol and triglycerides and changes; (7) the type and daily dosage of the statin therapy; (8) primary and secondary outcomes of the studies; (9) the mean period of follow-up.

\section{Study outcome}

The outcomes of interest were major adverse cardiovascular and cerebrovascular events (MACCE), including fatal or non-fatal myocardial infarction (MI), cardiac sudden death, indentified coronary heart disease (CHD), coronary revascularization (percutaneous coronary intervention or coronary artery bypass grafting), angina pectoris and fatal or non-fatal stroke. All-cause mortality was also evaluated across the trials.

\section{Statistical analysis}

The meta-analysis was performed according to the recommendations from the Cochrane Collaboration with Review Manager 5.0. The effect of statins on the occurrence of MACCE or each event was presented as odds ratio (OR) with $95 \%$ confidence intervals $(\mathrm{CI})$ using a fixed-effects model. Alternatively, randomeffects meta-analyses were performed when between-study variability existed. Heterogeneity was quantified using the $I^{2}$ statistic ( $I^{2}$ represents the percentage of variability due to between-study variability.) We regarded $I^{2}$ of less than $25 \%$, $25-50 \%$, and greater than $50 \%$ as low, moderate and high amounts of heterogeneity, respectively. Publication bias was evaluated using the funnel plot. Results were considered statistically significant if $P<0.05$.

\section{Results}

\section{Eligible studies and baseline characteristics}

The electronic database search identified 7 studies, which fulfilled our eligibility criteria. The included studies enrolled a total of 12711 participants (6340 patients in statin-therapy group and 6371 in control-therapy group). The baseline characteristics of each study [6-12] were summarized in 8 Table 1 . We found

Table 1 Studies and baseline characteristics.

\begin{tabular}{|c|c|c|c|c|c|c|c|}
\hline Trial & AFCAPS/TexCAPS [8] & PROSPER [9] & HPS [10] & CARDS [11] & ASCOT-LLA [7] & ASPEN [6] & MEGA [12] \\
\hline first author and year & Downs JR 1998 & Shepherd J 2002 & HPS group 2003 & Colhoun H 2004 & Sever P 2005 & Knopp RH 2006 & Tajima N 2008 \\
\hline target population & $\begin{array}{l}\text { patients with } \\
\text { average or below } \\
\text { average cholesterol } \\
\text { levels }\end{array}$ & $\begin{array}{l}\text { older patients } \\
\text { with cardio- } \\
\text { vascular risk } \\
\text { factors }\end{array}$ & $\begin{array}{l}\text { patients with } \\
\text { non-fasting } \\
\text { cholesterol } \\
\text { at least } \\
3.5 \mathrm{mmol} / \mathrm{l}\end{array}$ & $\begin{array}{l}\text { patients without } \\
\text { high LDL-C level, } \\
\text { had one or more } \\
\text { of the following: } \\
\text { hypertension, } \\
\text { retinopathy, } \\
\text { smoking, micro- } \\
\text { albuminuria }\end{array}$ & $\begin{array}{l}\text { patients with } \\
\text { hypertension }\end{array}$ & $\begin{array}{l}\text { patients with } \\
\mathrm{LDL}-\mathrm{C} \\
<4.1 \mathrm{mmol} / \mathrm{l}\end{array}$ & $\begin{array}{l}\text { patients with } \\
\text { hypercholes- } \\
\text { terolemia }\end{array}$ \\
\hline $\begin{array}{l}\text { number of patients } \\
\text { (statin/control) }\end{array}$ & $\begin{array}{l}155 \\
(84 / 71)\end{array}$ & $\begin{array}{l}623 \\
(303 / 320)\end{array}$ & $\begin{array}{l}2912 \\
(1428 / 1410)\end{array}$ & $\begin{array}{l}2838 \\
(1428 / 1410)\end{array}$ & $\begin{array}{l}2532 \\
(1258 / 1274)\end{array}$ & $\begin{array}{l}1905 \\
(959 / 946)\end{array}$ & $\begin{array}{l}1746 \\
(853 / 893)\end{array}$ \\
\hline mean age (years) & 58.0 & 75.0 & $\mathrm{NA}(40-80)$ & 61.5 & 63.1 & 60.5 & 58.3 \\
\hline current smoking (\%) & 12 & 27 & NA & 22 & 20 & 13 & 20 \\
\hline hypertension (\%) & 22 & 62 & NA & 84 & 100 & 52 & 42 \\
\hline $\begin{array}{l}\text { mean body mass } \\
\text { index }\left(\mathrm{Kg} / \mathrm{m}^{2}\right)\end{array}$ & 27 & 27 & NA & 29 & 30 & 29 & 24 \\
\hline $\operatorname{HbA1c}(\%)$ & NA & NA & NA & 7.8 & NA & 7.6 & 6.9 \\
\hline statin type & lovastatin & pravastatin & simvastatin & atorvastatin & atorvastatin & atorvastatin & pravastatin \\
\hline dosage (mg/day) & $20-40$ & 40 & 40 & 10 & 10 & 10 & $10-20$ \\
\hline $\begin{array}{l}\text { baseline TC } \\
\text { (mmol/L) (\% change) }\end{array}$ & $\begin{array}{l}5.7 \\
(-19.3 \%)\end{array}$ & $\begin{array}{l}5.7 \\
(\mathrm{NA})\end{array}$ & NA & $\begin{array}{l}5.4 \\
(-21.8 \%)\end{array}$ & $\begin{array}{l}5.5 \\
(-18.3 \%)\end{array}$ & $\begin{array}{l}5.0 \\
(-19.8 \%)\end{array}$ & $\begin{array}{l}6.3 \\
(-11.0 \%)\end{array}$ \\
\hline $\begin{array}{l}\text { baseline LDL-C } \\
\text { (mmol/L) (\% change) }\end{array}$ & $\begin{array}{l}3.9 \\
(-26.5 \%)\end{array}$ & $\begin{array}{l}3.8 \\
(\mathrm{NA})\end{array}$ & NA & $\begin{array}{l}3.0 \\
(-33.9 \%)\end{array}$ & $\begin{array}{l}3.4 \\
(-27.6 \%)\end{array}$ & $\begin{array}{l}3.0 \\
(-30.5 \%)\end{array}$ & $\begin{array}{l}4.0 \\
(-18.0 \%)\end{array}$ \\
\hline $\begin{array}{l}\text { baseline HDL-C } \\
\text { (mmol/L) (\% change) }\end{array}$ & $\begin{array}{l}1.0 \\
(4.8 \%)\end{array}$ & $\begin{array}{l}1.3 \\
\text { (NA) }\end{array}$ & NA & $\begin{array}{l}1.4 \\
(4.0 \%)\end{array}$ & $\begin{array}{l}1.3 \\
(1.5 \%)\end{array}$ & $\begin{array}{l}1.2 \\
(1.9 \%)\end{array}$ & $\begin{array}{l}1.5 \\
(5.0 \%)\end{array}$ \\
\hline $\begin{array}{l}\text { baseline TG } \\
\text { (mmol/L) (\% change) }\end{array}$ & $\begin{array}{l}1.7 \\
(-12.7 \%)\end{array}$ & $\begin{array}{l}1.5 \\
(\mathrm{NA})\end{array}$ & NA & $\begin{array}{l}2.0 \\
(-15.9 \%)\end{array}$ & $\begin{array}{l}1.7 \\
(-12.6 \%)\end{array}$ & $\begin{array}{l}1.6 \\
(-4.7 \%)\end{array}$ & $\begin{array}{l}1.4 \\
(-7.0 \%)\end{array}$ \\
\hline outcomes & MACCE & MACCE & MACCE & $\begin{array}{l}\text { MACCE; CR; } \\
\text { death; stroke; }\end{array}$ & $\begin{array}{l}\text { MACCE; CR; } \\
\text { stroke }\end{array}$ & $\begin{array}{l}\text { MACCE; CR; } \\
\text { death; stroke; }\end{array}$ & $\begin{array}{l}\text { MACCE; } \\
\text { death; MI; } \\
\text { stroke; CI }\end{array}$ \\
\hline follow-up (years) & 5.2 & 3.2 & 4.8 & 3.9 & 3.3 & 4.0 & 5.3 \\
\hline
\end{tabular}




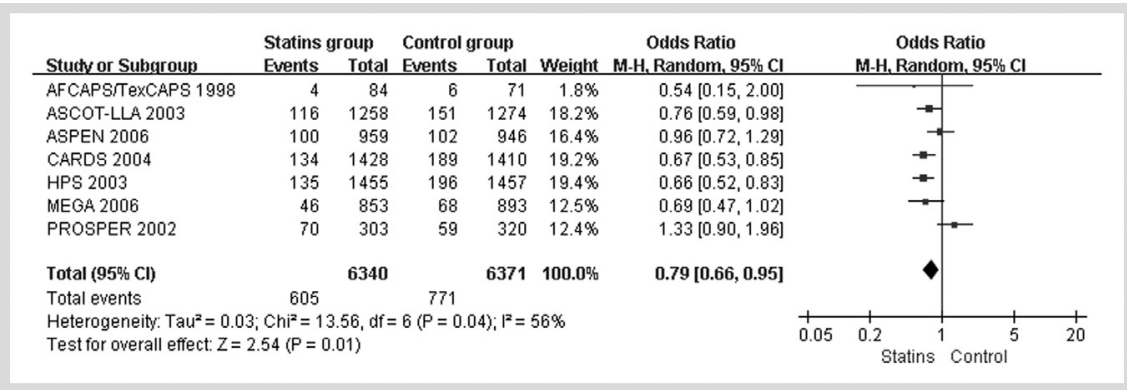

Fig. 1 Odds ratios of major adverse cardiovascular and cerebrovascular events associated with statin vs. control therapy in patients with diabetes.

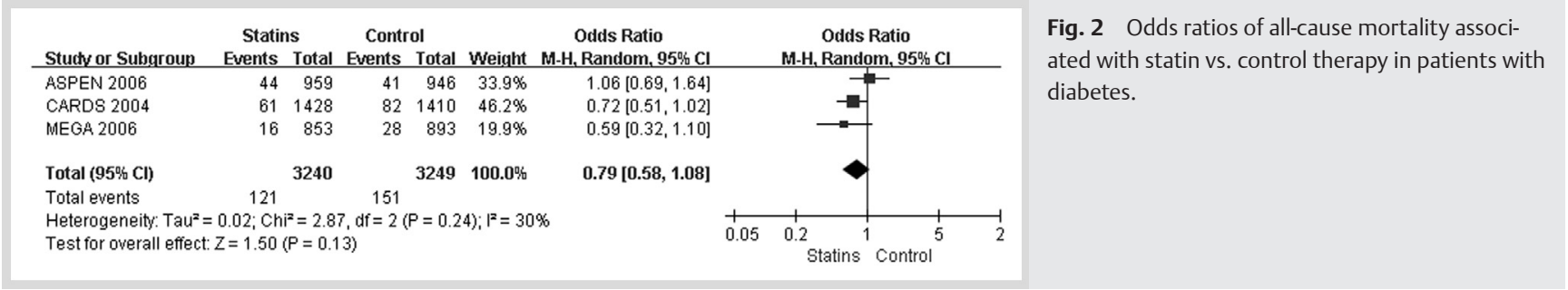

\begin{tabular}{|c|c|c|c|c|c|c|c|c|c|c|}
\hline Stucty or Subgroup & $\begin{array}{c}\text { Statin } \\
\text { Events }\end{array}$ & $\begin{array}{l}\text { is } \\
\text { Total }\end{array}$ & $\begin{array}{l}\text { Contrc } \\
\text { Events }\end{array}$ & & & Odds Ratio & \multirow{2}{*}{\multicolumn{3}{|c|}{$\begin{array}{c}\text { Odds Ratio } \\
\text { M-H, Fixed, 95\% } \mathrm{Cl}\end{array}$}} & \multirow{9}{*}{$\begin{array}{l}\text { Fig. } 3 \text { Odds ratios of stroke associated with statir } \\
\text { vs. control therapy in patients with diabetes. }\end{array}$} \\
\hline ASCOT-LLA 2003 & 28 & 1258 & 41 & 1274 & $324 \%$ & $M-H_{1}, F \mid x e(6,95 \%, C l$ & & & & \\
\hline ASPEN 2006 & 27 & 959 & 29 & 946 & $23.1 \%$ & & & & & \\
\hline CARDS 2004 & 21 & 1428 & & 1410 & $28.2 \%$ & $0.59[0.34,1.01]$ & & $\rightarrow-$ & & \\
\hline MEGA 2006 & 14 & 853 & 21 & 893 & $16.4 \%$ & $0.69[0.35,1.37]$ & & $\longrightarrow$ & & \\
\hline 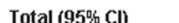 & & 4498 & & 4523 & $100,0^{0.4}$ & $0,1[0.54,0.94]$ & & - & & \\
\hline Total events & 90 & & 126 & & & & & & & \\
\hline \multirow{2}{*}{\multicolumn{7}{|c|}{$\begin{array}{l}\text { Heterogeneity: } \mathrm{Ch}^{2}=1.38, \mathrm{df}=3(P=0.71) ; \mathrm{I}^{2}=0 \% \\
\text { Test for overall effect: } Z=2.44(P=0.01)\end{array}$}} & 005 & & 20 & \\
\hline & & & & & & & & Statins Control ${ }^{3}$ & & \\
\hline
\end{tabular}

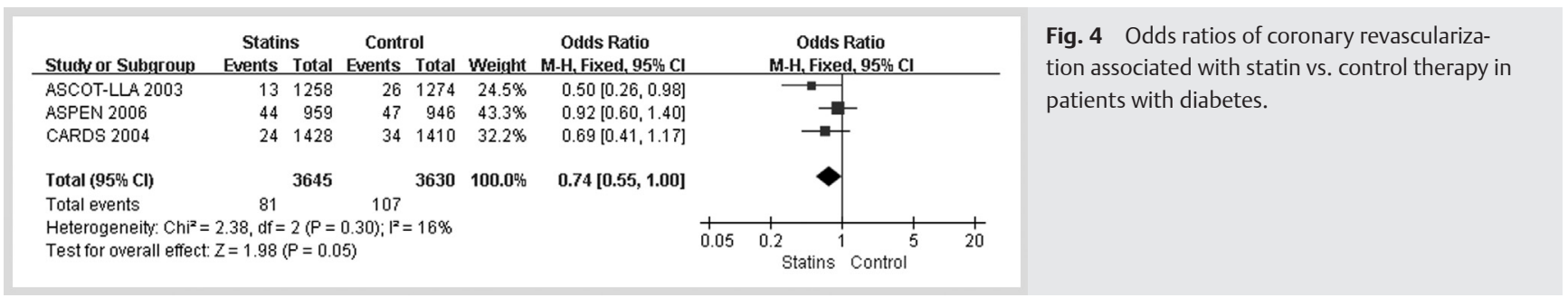

that basic cholesterol levels were mildly elevated in the target patients, while basic triglycerides levels were normal.

\section{Effect of statin therapy on MACCE}

There were 7 studies reported the MACCE data after at least 3.2 years follow-up. A total of 12711 patients were enrolled, including 6340 patients in statin-therapy group and 6371 in controltherapy group. A total of 1376 MACCE occurred during follow-up, with $9.54 \%$ (605 patients) in the statin therapy group and $12.10 \%$ (771 patients) in control group. Statin therapy was associated with a significant reduction in the incidence of MACCE (0.79, 95\%CI 0.66-0.95; $P=0.01$; $\odot$ Fig. 1).

\section{Effect of statin therapy on all-cause mortality}

With regard to the effect of statin on the all-cause mortality, there were 272 events among 6489 patients in 3 trials. The allcause mortality was $3.73 \%$ among statin therapy group, which was similar to the rate $(4.65 \%)$ among control group $(P=0.13$, $\odot$ Fig. 2).

\section{Effect of statin therapy on stroke}

A total of 216 stroke events occurred in 4 studies, including fatal and non-fatal stroke. There were 90 cases $(2.0 \%)$ of stroke among statin therapy patients and 126 cases $(2.79 \%)$ among controltherapy patients ( $\bullet$ Fig. 3). The risk of stroke was reduced $29 \%$ in statin therapy group $(0.71,95 \% \mathrm{CI} 0.54-0.94 ; P=0.01)$ by the fixed effects model, with no significant heterogeneity $(P=0.71)$

\section{Effect of statin therapy on coronary revascularization}

Patients with diabetes, treated with statin or placebo, differed significantly with respect to the risk of coronary revascularization (including percutaneous coronary intervention or coronary artery bypass grafting) in 3 trials. There were 81 cases $(2.22 \%)$ of coronary revascularization in statin group and 107 cases $(2.95 \%)$ in control group $(0.74,95 \% \mathrm{CI} 0.55-1.00 ; P=0.05$ and $P=0.30$ for heterogeneity), shown in $\odot$ Fig. 4. 


\section{Publication bias}

Funnel plots were performed for all outcomes, including the incidence of MACCE, mortality, stroke and coronary revascularization were symmetrically displayed.

\section{Discussion \\ $\checkmark$}

The present meta-analysis suggests that for primary prevention in patients with diabetes without established cardiovascular disease, statin therapy could reduce the cardiovascular and cerebrovascular events, but not all-cause mortality.

As one of confirmed risk factors, diabetes mellitus is not only associated with a 2- to 4-fold increase in the risk of coronary artery disease (CAD), but also related to its severity $[13,14]$. In 2001, the National Cholesterol Education Program (NCEP) Adult Treatment Panel III (ATP III) report elevated diabetes from a CHD risk factor to a CHD risk equivalent. Meanwhile, ATP III also recommended the initiation of pharmacotherapy for patients with a CHD risk equivalent (the presence of diabetes, peripheral arterial disease, abdominal aortic aneurysm, carotid artery disease or multiple risk factors with a 10-year Framingham risk of CHD of $>20 \%$ ) and an LDL-C concentration of $\geq 130 \mathrm{mg} / \mathrm{dl}$ [15]. Current medical evidence $[2,3]$ suggested that lipid-lowering medications could lead to a significant reduction in major cardiovascular events in patients with diabetes. As one of lipidlowering medications, statin has been considered to play a very important role in reducing the mortality of coronary artery disease $[4,16,17]$.

However, with regard to the primary prevention, conflicting evidence has resulted in controversy regarding the use of statins in patients with diabetes without established cardiovascular disease. A significant $37 \%$ reduction in risk of cardiovascular events was observed with atorvastatin in CARDS, and a significant 33\% reduction in risk of cardiovascular events was observed in HPS. However, in the study of ASCOT-LLA [7], a nonsignificant 16\% reduction in coronary heart disease death and nonfatal myocardial infarction was observed with $10 \mathrm{mg}$ of atorvastatin in patients with diabetes. Moreover, in the study of ASPEN [6], $10.4 \%$ of atorvastatin-treated patients without prior MI or interventional procedure experienced a primary cardiovascular end point, which was similar to the incidence in placebo-treated subjects $(10.8 \%, P>0.05)$. Researchers did not find a significant reduction in the primary composite end point comparing $10 \mathrm{mg}$ of atorvastatin with placebo (13.7 and $15.0 \%, P>0.05)$. When compared with CARDS, primary prevention patients in ASPEN were younger and less hypertensive and included less smokers and men. The low risk of CHD in primary prevention patients with diabetes may account for the unpromising result. Therefore, we designed this meta-analysis to clarify the efficacy of statin on primary prevention of cardiovascular and cerebrovascular events in patients with diabetes without established cardiovascular diseases.

A total of 7 trials were ultimately included in this meta-analysis, involving 12711 patients with diabetes without established cardiovascular diseases (6340 randomized to the statin-therapy group and 6371 randomized to the control-therapy group). After analysis the incidence of total MACCE, we found that statin therapy reduced $21 \%$ incidence of MACCE, which benefited the patients with diabetes for the primary prevention. In addition, statin therapy also reduced the risk of stroke $(29 \%)$ and coronary revascularization (26\%) in patients with diabetes, although the change of all-cause mortality did not reach the statistical difference. The results indicated that statin therapy in low risk patients, even without established coronary heart disease, myocardial infarction and stroke, did benefit for the primary prevention.

As regards with primary prevention, it should be taken into account for cost performance. It had been confirmed in previous studies that different type and different dosage of statin had different efficacy on the level of cholesterol and risk reduction of cardiovascular events $[18,19] .10 \mathrm{mg}$ atorvastatin could decrease the serum level of LDL-C by $30-40 \%$. In order to achieve the similar effects, lovastatin should increase to $40-80 \mathrm{mg}$, while simvastatin was $20 \mathrm{mg}$ [20]. However, it was interesting that we did not find more benefit from the usage of higher dosage or stronger efficacy of statins in our meta-analysis. For example, although the reduced ratio of MACCE was similar between the study of MEAG [31\%, (OR 0.69, 95\%CI 0.47-1.02)] and CARDS [33\%, (OR $0.67,95 \% \mathrm{CI} 0.53-0.85)]$, the dosage and types of statin were quite different. In the study of MEGA, the statin usage was $10-20 \mathrm{mg}$ pravastatin daily, which reduced the level of LDL-C by $18 \%$, while $10 \mathrm{mg}$ atorvastatin reduced the serum level of LDL-C by $33 \%$ in the study of CARDS. These data implied us that higher dosage of statin or greater reduction of LDL-C should not be the sole consideration of various factors in primary prevention for patients with diabetes. The benefit might be offset by the side effects of large dosage of different statins. In the present metaanalysis, we also investigated whether different type of statin had different efficacy on reduction in the incidence of MACCE. We conduct a sub-analysis by including 3 trials (CARDS, ASCOTLLA and ASPEN), which atorvastatin was assigned in the studies, and found that the MACCE $(0.78,95 \% \mathrm{CI} 0.63-0.95 ; P=0.01)$ was similar to the MACCE $(0.79,95 \% \mathrm{CI} 0.66-0.95 ; P=0.01)$ when all the statin trials were included. These data implied that for the primary prevention, the benefits of statin therapy are likely to be similar.

Our study had several limitations. First, this meta-analysis was limited by the lack of complete availability of relevant data. Data of all-cause mortality, cardiac mortality, stroke and myocardial infarction were not available in some included studies. Therefore, there may be reporting bias in these outcomes. Especially, all-cause mortality was only reported in 3 trials which suggested this analysis might be underpowered on all-cause mortality. Second, the usage of other medicine, such as ACEI/ARB, beta-blocker and aspirin, were not unclear. It has been clearly demonstrated that these medicine might influence the incidence of cardiovascular events. Third, longer follow-up period was needed for the primary prevention, which would be more meaningful for guiding further therapeutic plan.

\section{Conclusions}

\section{$\nabla$}

For primary prevention in patients with diabetes without established cardiovascular disease, statin therapy could reduce the cardiovascular and cerebrovascular events, but not all-cause mortality.

\section{Acknowledgments}

$\nabla$

None. 
Conflict of Interest: None.

\section{References}

1 Yang $W$, Lu J, Weng $J$ et al. Prevalence of diabetes among men and women in China. N Engl J Med 2010; 362: 1090-1101

2 Brugts JJ, Yetgin T, Hoeks SE et al. The benefits of statins in people without established cardiovascular disease but with cardiovascular risk factors: meta-analysis of randomised controlled trials. BMJ 2009; 338: b2376

3 Vijan S, Hayward RA. Pharmacologic lipid-lowering therapy in type 2 diabetes mellitus: background paper for the American College of Physicians. Ann Intern Med 2004; 140: 650-658

4 Sacks FM, Pfeffer MA, Moye LA et al. The effect of pravastatin on coronary events after myocardial infarction in patients with average cholesterol levels. N Engl J Med 1996; 335: 1001-1009

5 Cholesterol Treatment Trialists' (CTT) Collaborators. Kearney PM, Blackwell L, Collins R et al. Efficacy of cholesterol-lowering therapy in 18686 people with diabetes in 14 randomised trials of statins: a meta-analysis. Lancet 2008; 371: 117-125

6 Knopp RH, d'Emden M, Smilde JG et al. Efficacy and safety of atorvastatin in the prevention of cardiovascular end points in subjects with type 2 diabetes: the Atorvastatin Study for Prevention of Coronary Heart Disease Endpoints in non-insulin-dependent diabetes mellitus (ASPEN). Diabetes Care 2006; 29: 1478-1485

7 Sever PS, Poulter NR, Dahlöf B et al. Reduction in cardiovascular events with atorvastatin in 2532 patients with type 2 diabetes: Anglo-Scandinavian Cardiac Outcomes Trial-lipid-lowering arm (ASCOT-LLA). Diabetes Care 2005; 28: 1151-1157

8 Downs JR, Clearfield $M$, Weis $S$ et al. Primary prevention of acute coronary events with lovastatin in men and women with average cholesterol levels: results of AFCAPS/TexCAPS. Air Force/Texas Coronary Atherosclerosis Prevention Study. JAMA 1998; 279: 1615-1622

9 Shepherd J, Blauw GJ, Murphy MB et al. Pravastatin in elderly individuals at risk of vascular disease (PROSPER): a randomised controlled trial. Lancet 2002; 360: 1623-1630

10 Collins R, Armitage J, Parish S et al. MRC/BHF Heart Protection Study of cholesterol-lowering with simvastatin in 5963 people with diabetes: a randomised placebo-controlled trial. Lancet 2003; 361: 2005-2016
11 Colhoun HM, Betteridge DJ, Durrington PN et al. Primary prevention of cardiovascular disease with atorvastatin in type 2 diabetes in the Collaborative Atorvastatin Diabetes Study (CARDS): multicentre randomized placebo-controlled trial. Lancet 2004; 364: 685-696

12 Tajima $N$, Kurata $H$, Nakaya $N$ et al. Pravastatin reduces the risk for cardiovascular disease in Japanese hypercholesterolemic patients with impaired fasting glucose or diabetes: diabetes subanalysis of the Management of Elevated Cholesterol in the Primary Prevention Group of Adult Japanese (MEGA) Study. Atherosclerosis 2008; 199: 455-462

13 Lemp GF, Vander Zwaag R, Hughes JP et al. Association between the severity of diabetes mellitus and coronary arterial atherosclerosis. Am J Cardiol 1987; 60: 1015-1019

14 Beckman JA, Creager MA, Libby P. Diabetes and atherosclerosis: epidemiology, pathophysiology, and management. JAMA 2002; 287: 2570-2581

15 Expert Panel on Detection, Evaluation, and Treatment of High Blood Cholesterol in Adults. Executive Summary of the Third Report of the National Cholesterol Education Program (NCEP) Expert Panel on Detection, Evaluation, and Treatment of High Blood Cholesterol in Adults (Adult Treatment Panel III). JAMA 2001; 285: 2486-2497

16 Prevention of cardiovascular events and death with pravastatin in patients with coronary heart disease and a broad range of initial cholesterol levels. The Long-Term Intervention with Pravastatin in Ischaemic Disease (LIPID) Study Group. N Engl J Med 1998; 339: 1349-1357

17 Baigent C, Keech A, Kearney PM et al. Efficacy and safety of cholesterollowering treatment: prospective meta-analysis of data from 90056 participants in 14 randomised trials of statins. Lancet 2005; 366 : 1267-1278

18 Pedersen TR, Faergeman O, Kastelein JJ et al. High-dose atorvastatin vs. usual-dose simvastatin for secondary prevention after myocardial infarction: the IDEAL study: a randomized controlled trial. JAMA 2005; 294: 2437-2445

19 Pedersen TR, Cater NB, Faergeman 0 et al. Comparison of atorvastatin $80 \mathrm{mg} /$ day versus simvastatin 20 to $40 \mathrm{mg} /$ day on frequency of cardiovascular events late (five years) after acute myocardial infarction (from the Incremental Decrease in End Points through Aggressive Lipid Lowering [IDEAL] trial). Am J Cardiol 2010; 106: 354-359

20 Weng TC, Yang YH, Lin SJ et al. A systematic review and meta-analysis on the therapeutic equivalence of statins. J Clin Pharm Ther 2010; 35: 139-151 